\title{
Public health policy to redress iodine insufficiency in pregnant women may widen sociodemographic disparities
}

\author{
Simonette R Mallard* and Lisa A Houghton \\ Department of Human Nutrition, University of Otago, PO Box 56, Dunedin 9054, New Zealand
}

Submitted 30 January 2013: Final revision received 8 May 2013: Accepted 15 May 2013: First published online 19 June 2013

\begin{abstract}
Objective: To evaluate the impact of a mandatory bread fortification programme on estimated iodine intakes of childbearing women and to describe the extent to which uptake of a maternal iodine supplement recommendation is associated with sociodemographic characteristics.

Design: A postpartum survey was conducted using a self-administered questionnaire. Details on pre- and post-conceptional supplement use, bread intake, iodized salt use and maternal sociodemographic and obstetric characteristics were obtained.

Setting: Eleven maternity wards and hospitals located across New Zealand.

Subjects: Seven hundred and twenty-three postpartum New Zealand women.

Results: Mean iodine intake from fortified bread was $37 \mu \mathrm{g} / \mathrm{d}$ prior to conception. Younger women, women with higher parity, single women and those with unplanned pregnancies were less likely to meet the pregnancy Estimated Average Requirement (EAR) for iodine (all $P \leq 0 \cdot 022$ ). Although not statistically significant for all months of pregnancy, women with less education and income were less likely to meet the EAR $(P \leq 0 \cdot 11$ and $P \leq 0 \cdot 2$ for all months, respectively) and indigenous Māori women and Pacific women were less likely than New Zealand Europeans to meet the EAR ( $P \leq 0.17$ and $P \leq 0.051$ for all months, respectively). During pregnancy, iodine-containing supplement uptake at the recommended level $(150 \mu \mathrm{g} / \mathrm{d})$ was non-uniform across sociodemographic subgroups, with the most disadvantaged women benefiting the least from this public health policy. Conclusions: The disparities in supplement uptake noted here highlight the need for prioritizing further efforts towards universal salt iodization, such as the mandatory fortification of additional processed foods with iodized salt.
\end{abstract}

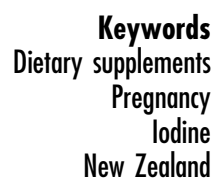

Iodine is essential for the production of thyroid hormones, which are required for the normal growth and neurocognitive development of the fetus, infant and child ${ }^{(1)}$. Because pregnancy is characterized by an increased demand for thyroid hormones, the iodine requirement of pregnant women is more than two-thirds higher than that of nonpregnant women ${ }^{(2)}$. Severe iodine deficiency during pregnancy can lead to miscarriage, stillbirth, congenital anomalies, perinatal mortality and cretinism in the offspring ${ }^{(3)}$. Mild-to-moderate iodine deficiency in pregnancy, particularly during the first trimester, has also been associated with cognitive deficits and neurobehavioural disorders in the offspring ${ }^{(4,5)}$.

Historically, iodine deficiency has primarily been considered a concern for developing countries; however, suboptimal iodine status among pregnant women has been reported recently in developed countries including Australia, New Zealand, the UK, Ireland, the USA, France, Spain and Hong Kong ${ }^{(2)}$. The WHO recommends universal salt iodization - the iodization of all salt for human and livestock consumption - as the optimal strategy for the prevention of iodine deficiency ${ }^{(6)}$. In addition, in areas where the proportion of households using iodized salt has yet to reach $90 \%$, the WHO recommends iodine supplementation be made available to all women capable of reproduction, currently pregnant or lactating ${ }^{(6)}$.

In response to the re-emergence of iodine deficiency in Australia and New Zealand, the joint governmental agency, Food Standards Australia New Zealand, mandated the replacement of non-iodized salt in all non-organic, yeast-leavened bread with iodized salt in late $2009^{(7)}$. As it was understood that the iodine requirements of pregnant and breast-feeding women remained unmet following this mandate, an iodine supplement recommendation of $150 \mu \mathrm{g} / \mathrm{d}$ throughout pregnancy and lactation was issued in both Australia and New Zealand in mid-2010 ${ }^{(8)}$. Iodine supplements were made available on prescription in New Zealand for a subsidized price (\$NZ 3) and some major Australasian supplement manufacturers reformulated their prenatal/lactation products to comply with the new recommendation; however, no formal public health educational campaign was initiated in New Zealand. 
The impact of bread fortification on the iodine intakes of New Zealand women before and during pregnancy has not yet been estimated, nor has the uptake of recommended maternal iodine supplementation. Given the disparities noted worldwide in the recommended uptake of folic acid supplements for pregnancy ${ }^{(9)}$, sociodemographic position may also be a particularly important factor in the uptake of iodine supplements. The aims of the present study were therefore to assess the impact of these two recently introduced public health policies on the estimated iodine intakes of women before and during pregnancy and to evaluate whether all segments of this target population have benefited equally from the maternal iodine supplement recommendation.

\section{Methods}

\section{Population}

The Vitamins and Minerals in Pregnancy Survey was a survey of postpartum New Zealand women between 7 March and 15 April, 2011. Twelve maternity wards/ hospitals, ten sites in New Zealand's six largest cities and two sites in smaller centres, were invited to participate based on their affiliation with the University of Otago. Eleven sites agreed to participate, including: Tauranga Hospital, Tauranga; Whakatane Hospital, Whakatane; River Ridge East Birth Centre, Waterford Birth Centre and Waikato Hospital, Hamilton; Hutt Hospital, Lower Hutt; Kenepuru Community Hospital and Wellington Hospital, Wellington; Christchurch Women's Hospital, Christchurch; Queen Mary Maternity Hospital, Dunedin; and Southland Hospital, Invercargill. Women were eligible for inclusion when they had delivered a healthy term infant, were aged 18 years or over and could communicate in English. Ethical approval for the study was obtained from the Multi-Region Ethics Committee of the New Zealand Ministry of Health (reference: MEC/11/EXP/004).

\section{Questionnaire}

Dietary supplement use, bread intake and iodized salt use before and during pregnancy were assessed using an anonymous, self-administered questionnaire developed with reference to similar questionnaires used elsewhere ${ }^{(10,11)}$. Questions on vitamin and mineral knowledge and maternal sociodemographic and obstetric characteristics were also included. Pre-testing and refinement of the questionnaire were undertaken with pregnant volunteers.

\section{Iodine intake from bread}

Usual daily intake of bread before pregnancy and during each trimester of pregnancy was queried. Participants were asked whether they ate non-organic, shop-bought bread. If yes, participants were asked how many slices of bread they consumed per day in the month before pregnancy and during months $1-3,4-6$ and 7-9 of pregnancy.
Using the analytically determined post-fortification level of $43 \mu \mathrm{g}$ iodine/100 $\mathrm{g}$ bread (range: $32-53 \mu \mathrm{g}$ iodine/100 $\mathrm{g}$ bread) ${ }^{(12)}$, one slice of bread with a median weight of $33 \mathrm{~g}^{(13)}$ was estimated to provide $14 \mu \mathrm{g}$ of iodine, with items such as rolls and buns being equivalent to two bread slices.

\section{Iodine intake from supplements}

A full-colour show card depicting photographs of all maternal supplements purchasable within New Zealand accompanied the questionnaire. Supplemental iodine intake for each individual was calculated based on reported supplement brand(s), if any, frequency of use (from twice daily to less than once weekly) and period of use (month before pregnancy, months 1, 2, and 3 of pregnancy and during trimesters 2 and 3 of pregnancy). Immediately following this survey, a major pregnancy supplement manufacturer reformulated its supplement to include iodine $(250 \mu \mathrm{g} / \mathrm{tablet})$, and thus all estimates here are based on the reformulated value to better assess the true impact of iodine supplementation in the New Zealand pregnant population.

\section{Iodine intake from food and salt}

Each participant was assigned an estimated baseline iodine intake from food of $60 \mu \mathrm{g} / \mathrm{d}$. This was the mean intake of women determined prior to the iodine fortification of bread in the 2003-2004 New Zealand Total Diet Survey, based on $14 \mathrm{~d}$ simulated diets ${ }^{(14)}$. Iodized salt use was excluded from the Total Diet Survey estimate. In our questionnaire, salt use before and during pregnancy was queried, with options including: iodized, noniodized/none and unsure. Participants who used iodized salt before or during pregnancy were assigned a further $48 \mu \mathrm{g}$ iodine/ $\mathrm{d}$, based on an estimated intake of $1 \mathrm{~g}$ discretionary salt $/ \mathrm{d}^{(7)}$ and an analytically determined median of $48 \mathrm{mg}$ iodine/ $\mathrm{kg}$ iodized salt ${ }^{(15)}$.

\section{Statistical analysis}

All analyses were conducted using the statistical software package Stata 11.1 and a two-sided 0.05 level of significance was used in all cases. Participants who nominated two or more ethnic groups were assigned to a single ethnic group using the prioritization system recommended by Statistics New Zealand ${ }^{(16)}$. Proportional to recent national maternity data ${ }^{(17)}$, under-represented age-ethnicity subgroups were weighted up and overrepresented subgroups were weighted down to ensure estimates were representative in terms of age and ethnicity. All analyses incorporated post-stratification weights and included sites as clusters to estimate robust standard errors. Mixed-model regression analyses were performed to estimate mean intakes and $95 \%$ confidence intervals of iodine from fortified bread, before and during pregnancy, with sites treated as random effects. Independent variables included: maternal age (three categories), parity 
(four categories), ethnicity (five categories), education (five categories), household income (five categories), relationship status (cohabiting $v$. not) and pregnancy intention (planned $v$. unplanned). Similarly, mixed-model regression analyses were used to estimate the proportion of women with mean iodine intakes from supplements below the New Zealand Ministry of Health recommendation for pregnancy $(150 \mu \mathrm{g} / \mathrm{d})^{(8)}$ and to estimate the proportion and $95 \%$ confidence interval of women with mean iodine intakes below the Estimated Average Requirement (EAR) for iodine before and during pregnancy $(107 \mu \mathrm{g}$ iodine/d and $179 \mu \mathrm{g}$ iodine/d, respectively). The proportion of a population with nutrient intakes beneath the EAR can be used to estimate the prevalence of inadequate intakes ${ }^{(18)}$. The EAR were derived from the WHO Recommended Nutrient Intakes for non-pregnant, non-lactating women (150 $\mu \mathrm{g}$ iodine/d) and pregnant women $(250 \mu \mathrm{g}$ iodine/d), using a conversion factor of 1.4 as recommended by the WHO and $\mathrm{FAO}^{(18)}$. Missing values for iodine intake from bread and supplements were treated as follows. Where a value was missing, the known bread or supplement value, the baseline intake $(60 \mu \mathrm{g} / \mathrm{d})$ and the intake from iodized salt ( $48 \mu \mathrm{g} / \mathrm{d}$ or none) were summed. If this did not reach the EAR cut-off, the total intake value was classified as missing. In the case of missing data on iodized salt use, or if a participant had selected 'unsure' for iodized salt use, where the total intake value would not have reached the specified cutoff had the participant used iodized salt (i.e. the partial total was more than $48 \mu \mathrm{g} / \mathrm{d}$ below the cut-off), the individual was classified as having not met the cut-off. In all cases where the partial total reached or exceeded the EAR cut-off, the individual was classified as having met that cut-off.

\section{Results}

\section{Study sample characteristics}

Of the 968 women invited to participate, 723 (75\%) agreed and met all inclusion criteria. Median maternal age was 31 years, similar to the national median recorded in the year ended March 2011 (30 years) ${ }^{(19)}$. Almost half of all deliveries were to primiparous women (45\%) and $44 \%$ of all pregnancies were unplanned. Two-thirds (66\%) of women held a post-secondary qualification, and $42 \%$ reported an annual household income below the national median for 2010 (\$NZ 64272) ${ }^{(20)}$. Compared with recent national maternity data, this sample had a higher proportion of New Zealand Europeans ( $65 \%$ v. 55\%), a lower proportion of Māori (14\% v. 20\%) and Pacific women (5\%v. $11 \%)$, and a similar proportion of Asians $(9 \% v .11 \%)^{(17)}$.

\section{Effect of bread fortification on estimated iodine intakes of women prior to pregnancy}

Prior to pregnancy, $20 \%$ of women reported that they did not use iodized salt and a further $7 \%$ were unsure of what type of salt they used. On average, fortified bread provided $37 \mu \mathrm{g}$ iodine/d before pregnancy (Table 1). Younger women, women with greater parity, Māori and Pacific women, women with the least income and education, single women and women with unplanned pregnancies attained statistically significantly higher mean iodine intakes from bread than their counterparts (all $P \leq 0.043$ ). An estimated $22 \%$ of those surveyed would have fallen below the EAR for non-pregnant, non-lactating women without the iodine fortification of bread (Table 2). Including iodine intake from fortified bread, the overall proportion of non-pregnant women falling below the EAR was reduced to $16 \%$. The least advantaged women benefited the most from the mandatory fortification of bread, with a reduction of up to two-thirds in the proportion falling below the EAR in some groups.

\section{Combined effect of supplement recommendation and bread fortification on estimated iodine intakes before and during pregnancy}

Overall, $16 \%$ of all women and $28 \%$ of women with planned pregnancies took supplements containing iodine in the month before conception, the majority ( $>90 \%)$ of which were commercial prenatal supplements. Including intake from food, iodized salt, fortified bread and supplements, an estimated $13 \%$ of women failed to attain the EAR in the month before conception.

In the first month of pregnancy, over two-thirds of women did not meet the pregnancy EAR (Table 3). By the third month of pregnancy, this had decreased to approximately half of all women, and remained at this level during months 4-9. When estimated excluding the iodine contributed by the reformulated commercial supplement, the proportion below the EAR was considerably greater at $84 \%$ in month $1,76 \%$ in month $2,71 \%$ in month 3 and $62 \%$ in months $4-9$ (data not shown).

Younger women, women with higher parity, single women and those with unplanned pregnancies were more likely to have mean iodine intakes beneath the EAR throughout pregnancy (all $P \leq 0 \cdot 022$ ). Women with less education and income, and those who had not received pregnancy-related iodine information, were also less likely to meet the EAR; however, this was not statistically significant for all months. Pairwise comparisons revealed that indigenous Māori women were less likely than New Zealand Europeans to meet the EAR in months 2, 3 and 4-9 of pregnancy (all $P \leq 0 \cdot 041$, data not shown). Similarly, Pacific women were less likely than New Zealand Europeans to meet the EAR in months 1,2 and 3 of pregnancy (all $P \leq 0 \cdot 007$, data not shown).

\section{Supplement uptake by sociodemographic subgroup}

Across the first three months of pregnancy, uptake of iodine supplementation at or above the New Zealand Ministry of Health's recommended level for pregnancy $(150 \mu \mathrm{g} / \mathrm{d})^{(8)}$ increased progressively (Fig. 1(a) to Fig. 1(f)). 
Table 1 Mean iodine intakes from bread fortified with iodized salt* before and during pregnancy: postpartum New Zealand (NZ) women, Vitamins and Minerals in Pregnancy Survey, 2011

\begin{tabular}{|c|c|c|c|c|c|c|c|c|c|c|}
\hline \multirow[b]{3}{*}{ Maternal characteristic } & \multirow[b]{3}{*}{$n$} & \multicolumn{9}{|c|}{ Mean iodine intake from fortified bread } \\
\hline & & \multicolumn{3}{|c|}{ Month before conception } & \multicolumn{3}{|c|}{ Months $1-3$ of pregnancy } & \multicolumn{3}{|c|}{ Months 4-9 of pregnancy } \\
\hline & & $\mu \mathrm{g} / \mathrm{d} t$ & $95 \% \mathrm{Cl}$ & $P$ value & $\mu \mathrm{g} / \mathrm{d} t$ & $95 \% \mathrm{Cl}$ & $P$ value & $\mu \mathrm{g} / \mathrm{d} t$ & $95 \% \mathrm{Cl}$ & $P$ value \\
\hline $\begin{array}{l}\text { All respondents } \\
\text { Age (years) }\end{array}$ & 677 & 37 & 34,41 & $\begin{array}{c}<0.0001 \\
0.0008 \pm\end{array}$ & 40 & $\begin{array}{l}35,45 \\
40,58\end{array}$ & $\begin{array}{r}<0.0001 \\
0.002 \pm\end{array}$ & 43 & 37,49 & $<0.0001$ \\
\hline$<25$ & 103 & 45 & 41,50 & & 49 & & & 50 & 41,59 & \\
\hline $25-34$ & 390 & 36 & 32,41 & & 40 & 33,47 & & 43 & 35,51 & \\
\hline$\geq 35$ & 181 & 34 & 30,39 & & 36 & 31,41 & & 39 & 34,43 & \\
\hline Parity & & & & $0.006 \ddagger$ & & & $0.021 \ddagger$ & & & $0.006 \ddagger$ \\
\hline Primiparous & 305 & 34 & 29,39 & & 37 & 31,44 & & 40 & 34,47 & \\
\hline 2 children & 197 & 34 & 30,38 & & 39 & 31,48 & & 40 & 31,49 & \\
\hline 3 children & 116 & 42 & 37,46 & & 41 & 36,47 & & 45 & 39,51 & \\
\hline$\geq 4$ children & 57 & 51 & 40,62 & & 53 & 43,63 & & 57 & 48,67 & \\
\hline Prioritized ethnicity & & & & 0.015 & & & $0 \cdot 11$ & & & $0 \cdot 2$ \\
\hline NZ European & 428 & 33 & 30,35 & & 36 & 33,39 & & 38 & 35,42 & \\
\hline Māori & 93 & 54 & 46,63 & & 60 & 44,76 & & 60 & 44,77 & \\
\hline Pacific & 35 & 45 & 32,58 & & 46 & 27,64 & & 52 & 32,71 & \\
\hline Asian & 56 & 28 & 18,37 & & 30 & 18,42 & & 33 & 21,44 & \\
\hline Other & 57 & 31 & 27,34 & & 32 & 28,36 & & 36 & 29,43 & \\
\hline Highest education qualification & & & & $0 \cdot 002 \ddagger$ & & & 0.021 & & & $0 \cdot 026$ \\
\hline$<$ High school & 92 & 53 & 41,65 & & 62 & 43,80 & & 62 & 44,81 & \\
\hline High school & 132 & 40 & 33,46 & & 41 & 34,48 & & 44 & 37,51 & \\
\hline Vocational training & 56 & 38 & 30,47 & & 46 & 37,54 & & 48 & 39,57 & \\
\hline Tertiary & 318 & 34 & 30,37 & & 36 & 32,39 & & 39 & 34,44 & \\
\hline Postgraduate & 70 & 26 & 18,35 & & 27 & 18,37 & & 30 & 20,40 & \\
\hline Annual household income (\$NZ) & & & & $0 \cdot 009 \ddagger$ & & & 0.006 & & & 0.012 \\
\hline$<40000$ & 157 & 44 & 33,54 & & 51 & 35,66 & & 55 & 38,72 & \\
\hline $41000-60000$ & 112 & 39 & 36,41 & & 39 & 36,43 & & 42 & 38,46 & \\
\hline $61000-80000$ & 103 & 37 & 31,44 & & 40 & 34,46 & & 43 & 37,49 & \\
\hline $81000-100000$ & 107 & 32 & 27,38 & & 33 & 29,37 & & 35 & 28,42 & \\
\hline$>100000$ & 169 & 31 & 27,35 & & 34 & 28,41 & & 36 & 30,41 & \\
\hline Relationship status & & & & 0.015 & & & 0.023 & & & 0.041 \\
\hline Single & 64 & 55 & 40,70 & & 59 & 41,76 & & 60 & 42,78 & \\
\hline Married/cohabiting & 611 & 35 & 32,38 & & 38 & 34,43 & & 41 & 36,47 & \\
\hline Pregnancy intention & & & & 0.043 & & & 0.026 & & & 0.008 \\
\hline Unplanned & 289 & 44 & 39,49 & & 47 & 39,52 & & 49 & 43,56 & \\
\hline Planned & 383 & 38 & 28,36 & & 36 & 29,42 & & 38 & 30,45 & \\
\hline
\end{tabular}

*Estimated iodine intake from iodine-fortified bread $=14 \mu \mathrm{g} / \mathrm{slice}(43 \mu \mathrm{g} \text { iodine/100 } \mathrm{g} \text { bread, } 1 \mathrm{slice}=33 \mathrm{~g})^{(12,13)}$. tWeighted by age and ethnicity and adjusted for clustering by site.

$\ddagger P$ value for linear trend.

However, uptake was not uniform across sociodemographic subgroups, with the least advantaged women being less likely to take supplements as recommended. Twenty-two per cent of women attained the recommended iodine intake from supplements in the first month of pregnancy. This proportion increased to $33 \%$ in the second month, $39 \%$ in the third month, and then declined to $35 \%$ in trimesters 2 and 3. From the second month of pregnancy, having received pregnancy-related iodine information approximately doubled the likelihood of taking iodine supplements as recommended, and those who received information also maintained high rates of uptake in the second and third trimesters. Less than half (49\%) of all women received pregnancy-related iodine information before or during pregnancy.

\section{Discussion}

Given the implications for neurocognitive development, the decision to implement public health policies to redress iodine insufficiency in Australia and New Zealand was warranted and was in alignment with strategies advocated by the WHO. In doing so, our survey suggests that mandating the iodine fortification of bread has reduced the prevalence of inadequate iodine intakes among non-pregnant, non-lactating New Zealand women by almost one-third, although women with lower bread intakes, such as women of Asian ethnicity and those with a postgraduate education, did not benefit to the same degree. Despite subsidizing the cost, recommended iodine supplement uptake during pregnancy was nonuniform across sociodemographic subgroups, with the most disadvantaged benefiting the least from this public health strategy, mirroring patterns noted worldwide for folic acid supplement uptake ${ }^{(21)}$. With a decreased likelihood of reaching their full intellectual potential, existing sociodemographic disparities faced by children born to younger women, women with higher parity, Māori and Pacific women, women with less education and income and single women may thus be further exacerbated. 
Table 2 Estimated proportion of women before conception with iodine intakes from food* below the Estimated Average Requirement $(E A R ; 107 \mu \mathrm{g} / \mathrm{d})$ as derived from WHO's Recommended Nutrient Intake $(150 \mu \mathrm{g} / \mathrm{d})$ for non-pregnant, non-lactating women ${ }^{(18)}$ : postpartum New Zealand (NZ) women, Vitamins and Minerals in Pregnancy Survey, 2011

\begin{tabular}{|c|c|c|c|c|c|c|c|}
\hline \multirow[b]{2}{*}{ Maternal characteristic } & \multirow[b]{2}{*}{$n$} & \multicolumn{3}{|c|}{ Without iodine fortification of bread } & \multicolumn{3}{|c|}{ Following iodine fortification of bread } \\
\hline & & $<\operatorname{EAR}(\%)+$ & $95 \% \mathrm{Cl}$ & $P$ value & $<$ EAR $(\%) \dagger$ & $95 \% \mathrm{Cl}$ & $P$ value \\
\hline $\begin{array}{l}\text { All respondents } \\
\text { Age (years) }\end{array}$ & 627 & 22 & 17,26 & $\begin{array}{c}<0.0001 \\
0.59\end{array}$ & 16 & 12,20 & $\begin{array}{c}<0.0001 \\
0.06 \ddagger\end{array}$ \\
\hline$<25$ & 82 & 25 & 17,33 & & 12 & 1,17 & \\
\hline $25-34$ & 365 & 20 & 12,27 & & 15 & 9,22 & \\
\hline$\geq 35$ & 172 & 23 & 19,28 & & 19 & 14,24 & \\
\hline Parity & & & & 0.42 & & & $0.004 \ddagger$ \\
\hline Primiparous & 283 & 24 & 18,29 & & 20 & 15,24 & \\
\hline 2 children & 183 & 19 & 13,26 & & 15 & 9,21 & \\
\hline 3 children & 110 & 20 & 11,29 & & 13 & 5,22 & \\
\hline$\geq 4$ children & 50 & 22 & 11,33 & & 5 & 0,12 & \\
\hline Prioritized ethnicity & & & & 0.66 & & & 0.001 \\
\hline NZ European & 403 & 22 & 16,27 & & 17 & 13,22 & \\
\hline Māori & 76 & 15 & 3,27 & & 5 & 0,11 & \\
\hline Pacific & 29 & 37 & 14,59 & & 22 & 2,42 & \\
\hline Asian & 57 & 18 & 10,26 & & 16 & 10,21 & \\
\hline Other & 51 & 27 & 17,36 & & 23 & 11,34 & \\
\hline Highest education qualification & & & & 0.26 & & & 0.47 \\
\hline$<$ High school & 78 & 29 & 16,42 & & 12 & 2,22 & \\
\hline High school & 110 & 21 & 12,31 & & 15 & 6,24 & \\
\hline Vocational training & 54 & 19 & 1,38 & & 11 & 1,22 & \\
\hline Tertiary & 305 & 17 & 11,23 & & 14 & 11,17 & \\
\hline Postgraduate & 68 & 28 & 14,43 & & 25 & 11,39 & \\
\hline Annual household income (\$NZ) & & & & $0 \cdot 21$ & & & 0.83 \\
\hline$<40000$ & 132 & 28 & 20,35 & & 15 & 6,23 & \\
\hline $41000-60000$ & 103 & 15 & 2,28 & & 13 & 2,23 & \\
\hline $61000-80000$ & 96 & 21 & 11,30 & & 17 & 9,24 & \\
\hline $81000-100000$ & 103 & 22 & 17,27 & & 18 & 14,23 & \\
\hline$>100000$ & 159 & 22 & 16,28 & & 18 & 13,23 & \\
\hline Relationship status & & & & $0 \cdot 26$ & & & 0.36 \\
\hline Single & 52 & 29 & 14,44 & & 10 & 0,25 & \\
\hline Married/cohabiting & 569 & 21 & 16,26 & & 16 & 12,20 & \\
\hline Pregnancy intention & & & & 0.35 & & & 0.02 \\
\hline Unplanned & 255 & 20 & 13,28 & & 12 & 5,19 & \\
\hline Planned & 367 & 23 & 19,27 & & 19 & 16,22 & \\
\hline Pregnancy-related iodine information§ & & & & 0.027 & & & 0.036 \\
\hline Did not receive & 546 & 23 & 18,28 & & 17 & 12,21 & \\
\hline Received & 79 & 14 & 7,21 & & 10 & 4,16 & \\
\hline
\end{tabular}

${ }^{*}$ Median iodine intake from foods (excluding iodine-fortified bread and iodized salt) $=60 \mu \mathrm{g} / \mathrm{d}^{(14)}$; estimated iodine intake from iodized salt, if used $=48 \mu \mathrm{g} / \mathrm{d}$

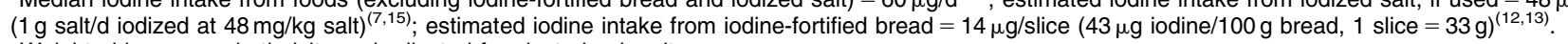
tWeighted by age and ethnicity and adjusted for clustering by site.

$\ddagger P$ value for linear trend.

§Information received prior to pregnancy only.

Few studies have examined the uptake of iodine supplement recommendations according to sociodemographic position. In a recent study in Poland, where prenatal iodine supplementation is also officially recommended, similar sociodemographic disparities were apparent in the uptake of iodine-containing supplements ${ }^{(22)}$. Several researchers have recently questioned the reliance upon iodine supplements as a means to provide coverage to all pregnant women, highlighting that official recommendations and associated educational campaigns may fail to benefit women of lower socio-economic position ${ }^{(23,24)}$. International evidence has shown that folic acid supplement campaigns meet with little success in lower socioeconomic groups ${ }^{(9)}$. Moreover, educational campaigns have been theorized to widen disparities by increasing supplement uptake among women receptive to such initiatives, but being unable to influence those least likely to use supplements ${ }^{(25)}$. Conversely, universal policies, such as mandatory food fortification, alter the underlying environment rather than attempt to modify behaviour and may therefore narrow inequalities in nutrient intakes ${ }^{(25)}$. The disparities in supplement uptake noted here, despite subsidizing the cost of supplements, thus highlight the need for prioritizing further efforts towards universal salt iodization, such as the mandatory fortification of additional processed foods with iodized salt.

In developed countries, more than three-quarters of salt intake is derived from processed foods ${ }^{(26,27)}$, somewhat limiting the effectiveness of salt iodization programmes unless food manufacturers use iodized salt. While voluntary use of iodized salt in processed foods is permitted in New Zealand, manufacturer uptake is minimal ${ }^{(7)}$. Following a recent worldwide survey of food manufacturers, it was concluded that iodized salt use in processed foods may need to be mandated to secure manufacturer uptake ${ }^{(28)}$. The initial report produced by Food Standards Australia 
Table 3 Estimated proportion of women during pregnancy with iodine intakes below the Estimated Average Requirement (EAR; 179 $\mu \mathrm{g} / \mathrm{d})$ as derived from the WHO's Recommended Nutrient Intake for pregnancy $(250 \mu \mathrm{g} / \mathrm{d})^{(18)}$, following the iodine fortification of bread and including supplement use*: postpartum New Zealand (NZ) women, Vitamins and Minerals in Pregnancy Survey, 2011

\begin{tabular}{|c|c|c|c|c|c|c|c|c|c|c|c|c|c|}
\hline \multirow[b]{2}{*}{ Maternal characteristic } & \multirow[b]{2}{*}{$n$} & \multicolumn{3}{|c|}{ Month 1 of pregnancy } & \multicolumn{3}{|c|}{ Month 2 of pregnancy } & \multicolumn{3}{|c|}{ Month 3 of pregnancy } & \multicolumn{3}{|c|}{ Months 4-9 of pregnancy } \\
\hline & & $<$ EAR $(\%) \dagger$ & $95 \% \mathrm{Cl}$ & $P$ value & $<$ EAR $(\%) \dagger$ & $95 \% \mathrm{Cl}$ & $P$ value & $<$ EAR $(\%) \dagger$ & $95 \% \mathrm{Cl}$ & $P$ value & $<\operatorname{EAR}(\%) \dagger$ & $95 \% \mathrm{Cl}$ & $P$ value \\
\hline $\begin{array}{l}\text { All respondents } \\
\text { Age (years) }\end{array}$ & 653 & 69 & 67,71 & $\begin{array}{r}<0.0001 \\
0.0001\end{array}$ & 58 & 55,61 & $\begin{array}{c}<0.0001 \\
0.006\end{array}$ & 51 & 46,56 & $\begin{array}{c}<0.0001 \\
0.004\end{array}$ & 50 & 43,57 & $\begin{array}{c}<0.0001 \\
0.001\end{array}$ \\
\hline$<25$ & 91 & 86 & 80,92 & & 73 & 65,81 & & 67 & 59,75 & & 64 & 53,74 & \\
\hline $25-34$ & 383 & 66 & 61,71 & & 56 & 49,62 & & 48 & 39,58 & & 47 & 36,57 & \\
\hline$\geq 35$ & 173 & 68 & 62,73 & & 56 & 50,62 & & 49 & 41,57 & & 49 & 41,56 & \\
\hline Parity & & & & $0.021 \ddagger$ & & & $0.02 \ddagger$ & & & $0.022 \ddagger$ & & & $0.005 \ddagger$ \\
\hline Primiparous & 295 & 66 & 60,71 & & 55 & 50,61 & & 47 & 41,54 & & 44 & 35,52 & \\
\hline 2 children & 190 & 67 & 61,74 & & 56 & 47,64 & & 50 & 40,59 & & 51 & 41,61 & \\
\hline 3 children & 114 & 73 & 64,82 & & 62 & 51,72 & & 55 & 43,67 & & 59 & 47,71 & \\
\hline$\geq 4$ children & 53 & 85 & 73,97 & & 74 & 62,86 & & 69 & 53,84 & & 63 & 49,78 & \\
\hline Prioritized ethnicity & & & & 0.08 & & & 0.09 & & & 0.08 & & & 0.08 \\
\hline NZ European & 416 & 65 & 61,70 & & 51 & 45,57 & & 43 & 38,49 & & 45 & 41,50 & \\
\hline Māori & 82 & 76 & 62,90 & & 67 & 55,78 & & 63 & 52,73 & & 62 & 49,75 & \\
\hline Pacific & 33 & 86 & 72,99 & & 81 & 67,95 & & 78 & 59,98 & & 72 & 45,98 & \\
\hline Asian & 55 & 60 & 37,83 & & 55 & 37,72 & & 44 & 22,65 & & 37 & 16,58 & \\
\hline Other & 57 & 69 & 56,83 & & 58 & 51,65 & & 55 & 46,64 & & 47 & 34,59 & \\
\hline Highest education qualification & & & & 0.012 & & & 0.07 & & & 0.008 & & & $0 \cdot 11$ \\
\hline$<$ High school & 84 & 78 & 67,89 & & 68 & 57,75 & & 59 & 45,73 & & 59 & 43,75 & \\
\hline High school & 126 & 75 & 63,88 & & 65 & 56,74 & & 65 & 54,76 & & 65 & 51,78 & \\
\hline Vocational training & 52 & 81 & 67,95 & & 72 & 56,88 & & 66 & 50,83 & & 52 & 27,78 & \\
\hline Tertiary & 314 & 61 & 59,64 & & 49 & 45,54 & & 41 & 34,47 & & 43 & 36,49 & \\
\hline Postgraduate & 68 & 68 & 50,86 & & 54 & 37,71 & & 43 & 26,60 & & 37 & 26,48 & \\
\hline Annual household income (\$NZ) & & & & $0.0002 \ddagger$ & & & 0.013 & & & 0.01 & & & $0 \cdot 2$ \\
\hline$<40000$ & 143 & 81 & 74,88 & & 72 & 63,80 & & 64 & 54,74 & & 61 & 47,76 & \\
\hline $40000-60000$ & 111 & 70 & 63,78 & & 62 & 56,67 & & 57 & 44,70 & & 55 & 41,70 & \\
\hline $61000-80000$ & 101 & 68 & 56,80 & & 56 & 45,67 & & 46 & 34,59 & & 46 & 33,58 & \\
\hline $81000-100000$ & 105 & 61 & 54,67 & & 43 & 32,54 & & 38 & 27,49 & & 34 & 25,44 & \\
\hline$>100000$ & 165 & 60 & 54,65 & & 48 & 39,57 & & 39 & 32,46 & & 45 & 38,52 & \\
\hline Relationship status & & & & 0.016 & & & 0.002 & & & 0.0002 & & & 0.003 \\
\hline Single & 59 & 80 & 71,89 & & 76 & 65,87 & & 72 & 63,82 & & 70 & 56,84 & \\
\hline Married/cohabiting & 590 & 68 & 66,71 & & 56 & 54,59 & & 49 & 43,55 & & 48 & 40,55 & \\
\hline Pregnancy intention & & & & $<0.0001$ & & & 0.003 & & & 0.004 & & & 0.001 \\
\hline Unplanned & 267 & 79 & 76,83 & & 67 & 61,74 & & 61 & 52,70 & & 60 & 51,70 & \\
\hline Planned & 382 & 61 & 57,64 & & 51 & 47,55 & & 44 & 40,48 & & 43 & 36,49 & \\
\hline Pregnancy-related iodine information & & & & 0.08 & & & 0.0002 & & & $<0.0001$ & & & $<0.0001$ \\
\hline Did not receive & 319 & 73 & 68,77 & & 67 & 63,71 & & 64 & 59,69 & & 68 & 62,74 & \\
\hline Received & 333 & 66 & 62,70 & & 49 & 44,54 & & 38 & 33,43 & & 32 & 25,40 & \\
\hline
\end{tabular}



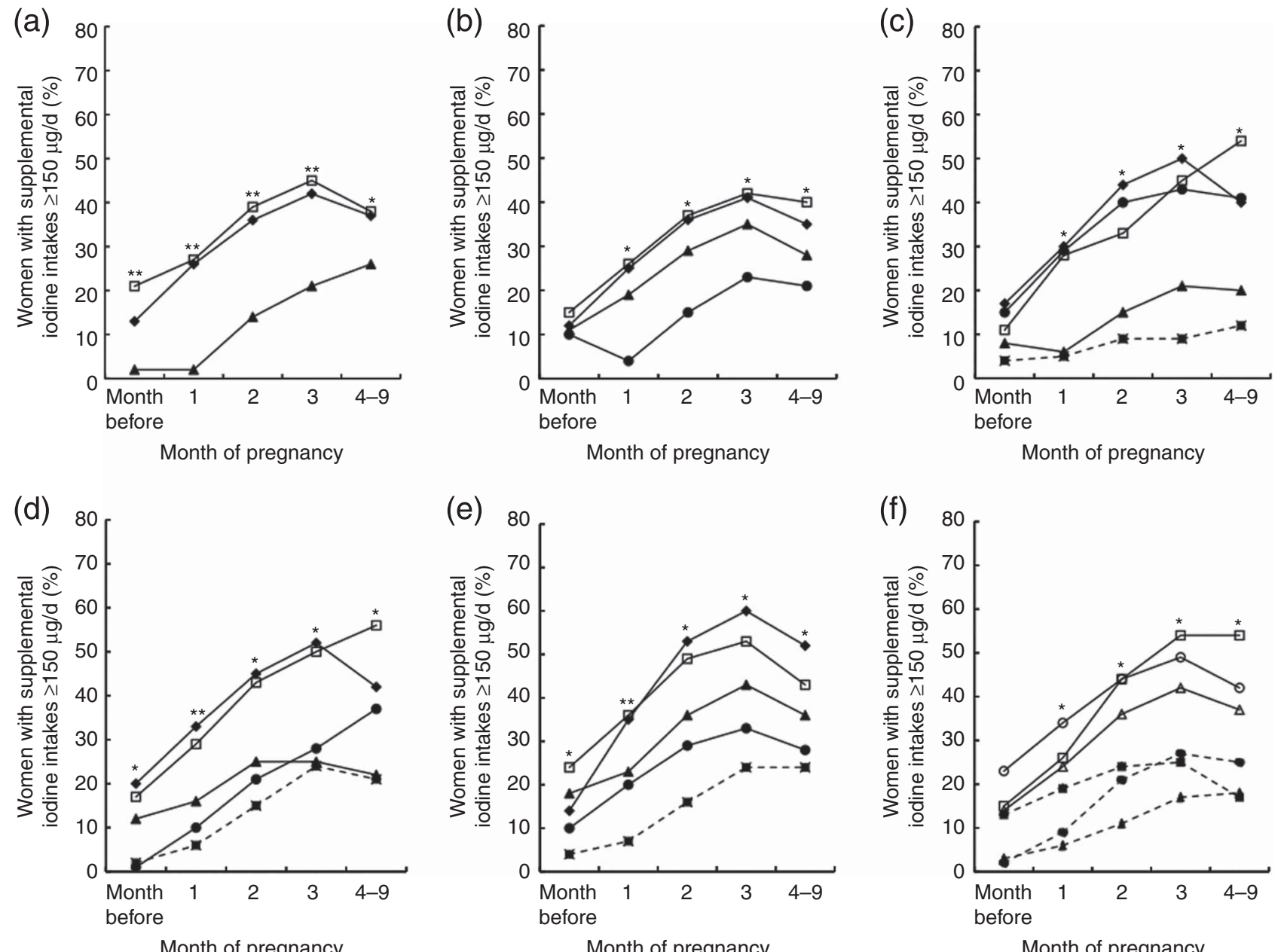

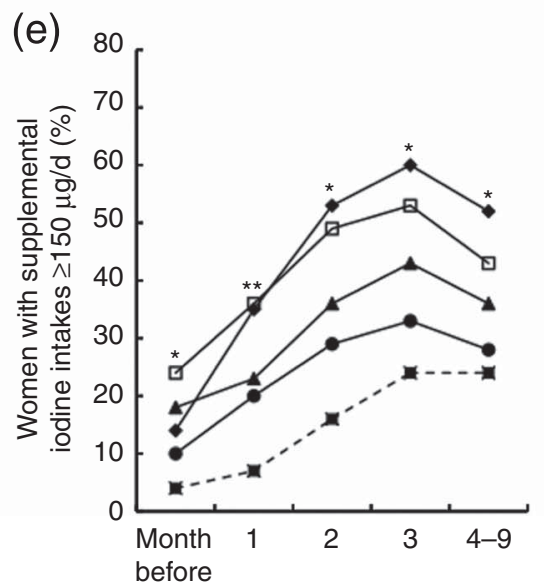

Month of pregnancy

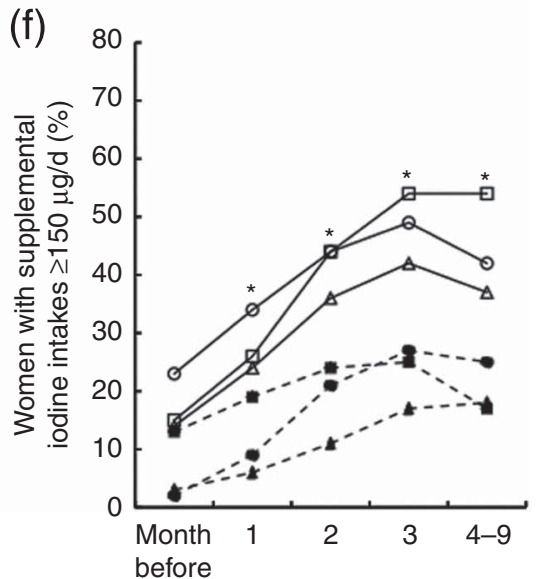

Month of pregnancy

Fig. 1 Proportion (\%) of postpartum New Zealand women with supplemental iodine intakes $\geq 150 \mu \mathrm{g} / \mathrm{d}$ according to: (a) age at

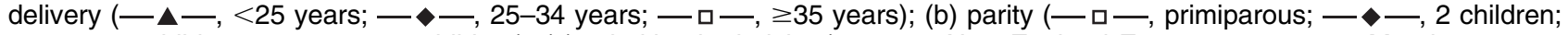

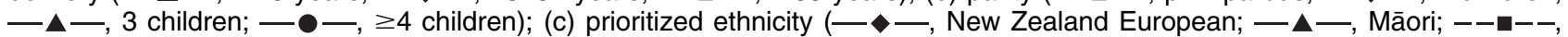

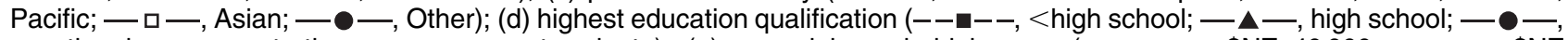
vocational; - - tertiary; - - - postgraduate); (e) annual household income (-- - - , < \$NZ 40000; - - \$NZ

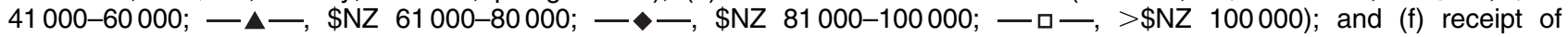
pregnancy-related iodine information (- - - received iodine information; - $-\mathbf{-}--$, did not receive iodine information), pregnancy intention ( $-0-$, planned pregnancy; - - - - , unplanned pregnancy) and relationship status $(-\Delta-$, married/ cohabiting; $--\boldsymbol{\Delta}--$, single). Weighted for age and ethnicity and adjusted for clustering by site $(n \geq 660)$; Vitamins and Minerals in Pregnancy Survey, 2011. ${ }^{\star} P \leq 0 \cdot 05,{ }^{\star \star} P \leq 0 \cdot 0001$

New Zealand considering the potential introduction of mandatory iodine fortification in New Zealand examined several fortification options ${ }^{(29)}$. Replacing salt in all processed foods with salt iodized at $15 \mathrm{mg} / \mathrm{kg}$ was explored, and was estimated to provide an additional $72 \mu \mathrm{g}$ iodine/d to women of reproductive age, excluding discretionary salt use. This option was rejected, along with universal salt iodization, in favour of the more logistically feasible alternative of replacing salt in yeast-leavened bread, biscuits, crackers and breakfast cereals with salt iodized at $20-45 \mathrm{mg} / \mathrm{kg}$. The proposed mandate was estimated to provide an additional $64 \mu \mathrm{g}$ iodine/d to New Zealand women of reproductive age, excluding discretionary salt use $^{(29)}$. Following public consultation, this proposal was also rejected. Major hurdles highlighted by the consultation process were the technological difficulty in iodizing large grains of crystallized rock salt (a common ingredient in crackers) evenly; the cost of running separate production lines for non-iodized export products; and the fact that many biscuits are imported ${ }^{(7)}$. Instead, in late 2009, the fortification of all yeast-leavened bread with salt iodized at $20-65 \mathrm{mg} / \mathrm{kg}$ was mandated ${ }^{(7)}$. We estimate the implementation of the mandate has resulted in an average additional iodine intake of $37 \mu \mathrm{g} / \mathrm{d}$ among women before pregnancy, slightly over half the achievable intake had salt in all processed foods been iodized at $15 \mathrm{mg} / \mathrm{kg}$.

Interpretation of the current study should be made in recognition of the approximate nature of the iodine intake results, specifically that they are a sum of number of estimated values and are based on recall. Moreover, to assess the true prevalence of inadequacy of dietary iodine intake, rigorous dietary assessment methods, such as the 
use of weighed food records over multiple days, should be employed and the group distribution of observed intakes should be adjusted for within-person variation ${ }^{(30)}$. In addition, the iodine content of foods in food composition tables should be both complete and accurate ${ }^{(31)}$. Due to the challenges of dietary intake assessment, most population estimates of iodine intake are derived from the median iodine concentration of spot urine samples; yet due to the day-to-day variability in dietary intakes, use of a single urinary iodine measurement also leads to overestimation of the percentage of the population below the $\operatorname{EAR}^{(32,33)}$. A further drawback of the use of urinary iodine to estimate dietary iodine intakes is that the contribution from specific iodine sources, such as fortified foods, cannot be determined. Despite these limitations, urinary iodine is regarded as a reliable indicator of dietary iodine intake during pregnancy ${ }^{(6)}$. Investigations are underway evaluating the sample size and number of repeated urine samples needed to adjust the population distribution of urinary iodine, which will be of considerable value to improving the accuracy of iodine intake assessment in this life-cycle group ${ }^{(32)}$.

The findings of the present study are of particular relevance to governments with established maternal iodine supplement recommendations, as well as to those yet to develop policy on such recommendations. Concerns over the potential for a low level of iodine supplement uptake among women of lower socioeconomic position have been raised previously ${ }^{(23)}$ and here we show that these concerns are valid. The ethics of proceeding with such an intervention are thus questionable, as public health strategies should aim to raise the average health of the population without widening disparities $^{(34)}$. While universal salt iodization remains the key strategy to prevent iodine deficiency, in its absence the widespread mandatory fortification of processed foods may be the best and most equitable means of providing adequate iodine to women throughout pregnancy. Encouraging an increase in the use of iodized salt in the home is also at odds with current public health recommendations to reduce $\mathrm{Na}$ intakes. A further alternative is to increase the concentration of salt iodization. In Switzerland, where $95 \%$ of households and $70 \%$ of food manufacturers use iodized salt, iodization was increased from 15 to $20 \mathrm{mg} / \mathrm{kg}$ salt in $1998^{(35)}$. Both pregnant women and schoolchildren in Switzerland now have adequate iodine intakes ${ }^{(35)}$, demonstrating that it is possible to safely meet the needs of most life-cycle groups in a population with a salt iodization strategy.

\section{Acknowledgements}

Sources of funding: This study was funded by the University of Otago, Dunedin, New Zealand. Conflict of interest: The authors declare no conflicts of interest.
Authors' contributions: S.R.M. designed the study and the data collection tools; monitored the data collection; cleaned and analysed the data; drafted the paper; and is guarantor. L.A.H. conceived the idea for the study; was involved in study design; monitored data collection; and revised the draft paper. Both authors read and approved the final manuscript. Acknowledgements: The authors thank Andrew Gray (Biostatistician, Department of Preventive and Social Medicine, University of Otago) for his contribution to survey design; dietetic students (Department of Human Nutrition, University of Otago) for participant recruitment and data entry; and Rosalind Gibson (Professor, Department of Human Nutrition, University of Otago) for her advice on the draft manuscript.

\section{References}

1. Melse-Boonstra A \& Jaiswal N (2010) Iodine deficiency in pregnancy, infancy and childhood and its consequences for brain development. Best Pract Res Clin Endocrinol Metab 24, 29-38.

2. Li M \& Eastman CJ (2012) The changing epidemiology of iodine deficiency. Nat Rev Endocrinol 8, 434-440.

3. Hetzel BS (1983) Iodine deficiency disorders (IDD) and their eradication. Lancet 2, 1126-1129.

4. Vermiglio F, Lo Presti VP, Moleti M et al. (2004) Attention deficit and hyperactivity disorders in the offspring of mothers exposed to mild-moderate iodine deficiency: a possible novel iodine deficiency disorder in developed countries. J Clin Endocrinol Metab 89, 6054-6060.

5. van Mil N, Tiemeier H, Bongers-Schokking JJ et al. (2012) Low urinary iodine excretion during early pregnancy is associated with alterations in executive functioning in children. J Nutr 142, 2167-2174.

6. World Health Organization, Andersson M, de Benoist B et al. (2007) Prevention and control of iodine deficiency in pregnant and lactating women and in children less than 2-years-old: conclusions and recommendations of the Technical Consultation. Public Health Nutr 10, 1606-1611.

7. Food Standards Australia New Zealand (2008) Final Assessment Report Proposal P230: Consideration of Mandatory Fortification with Iodine for New Zealand. Wellington: FSANZ.

8. New Zealand Ministry of Health (2010) Iodine. http:// www.health.govt.nz/our-work/preventative-health-wellness/ nutrition/iodine (accessed October 2012).

9. Ray J, Singh G \& Burrows R (2004) Evidence for suboptimal use of periconceptional folic acid supplements globally. BJOG 111, 399-408.

10. Dott M, Rasmussen SA, Hogue CJ et al. (2010) Association between pregnancy intention and reproductive-health related behaviors before and after pregnancy recognition, National Birth Defects Prevention Study, 1997-2002. Matern Child Health J 14, 373-381.

11. Charlton KE, Gemming L, Yeatman H et al. (2010) Suboptimal iodine status of Australian pregnant women reflects poor knowledge and practices related to iodine nutrition. Nutrition 26, 963-968.

12. Edmonds J \& Ryan T (2012) Dietary Iodine Intake of New Zealand Children Following the Fortification of Bread with Iodine. MAF Technical Paper no. 2012/02. Wellington: Ministry of Agriculture and Forestry.

13. Lesperance L (editor) (2009) The Concise New Zealand Food Composition Tables. Wellington: New Zealand Ministry of Health. 
14. Thomson BM, Vannoort RW \& Haslemore RM (2008) Dietary exposure and trends of exposure to nutrient elements iodine, iron, selenium and sodium from the 2003-4 New Zealand Total Diet Survey. Br J Nutr 99, 614-625.

15. Thomson B (2009) Levels of Iodine in New Zealand Retail Salt. Christchurch: Institute of Environmental Science \& Research Limited.

16. Statistics New Zealand (2005) Statistical Standard for Ethnicity. http://www2.stats.govt.nz/domino/external/web/ carsweb.nsf/55d63ae38ba3a25e4c2567e6007f6686/35d9b7e 17a1d6151cc25701100031353?OpenDocument (accessed October 2012).

17. New Zealand Ministry of Health (2011) Maternity Snapshot 2010: Provisional data. http://www.health.govt.nz/publication/ maternity-snapshot-2010-provisional-data (accessed October 2012).

18. Allen L, de Benoist B, Dary O et al. (editors) (2006) Guidelines on Food Fortification with Micronutrients. Geneva: WHO and FAO.

19. Statistics New Zealand (2011) Births and Deaths: Year ended March 2011. http://www.stats.govt.nz/browse_for_ stats/population/births/BirthsAndDeaths_HOTPYeMar11.aspx (accessed October 2012).

20. Statistics New Zealand (2010) New Zealand Income Survey: June 2010 quarter. http://www.stats.govt.nz/ /media/ Statistics/Browse\%20for\%20stats/NZIncomeSurvey/HOTP Jun10qtr/NZIncomeSurveyJun10qtrHOTP.pdf (accessed October 2012).

21. Mallard SR, Gray AR \& Houghton LA (2012) Delaying mandatory folic acid fortification policy perpetuates health inequalities: results from a retrospective study of postpartum New Zealand women. Hum Reprod 27, 273-282.

22. Milewicz T, Czyzewicz M, Stochmal E et al. (2011) Intake of iodine-containing multivitamin preparations by pregnant women from the Krakow region of Poland. Endokrynol Pol 62, 309-315.

23. Zimmermann MB \& Delange F (2004) Iodine supplementation of pregnant women in Europe: a review and recommendations. Eur J Clin Nutr 58, 979-984.
24. Untoro J, Timmer A \& Schultink W (2010) The challenges of iodine supplementation: a public health programme perspective. Best Pract Res Clin Endocrinol Metab 24, 89-99.

25. Sumar N \& McLaren L (2011) Impact on social inequalities of population strategies of prevention for folate intake in women of childbearing age. Am J Public Health 101, 1218-1224.

26. James W, Ralph A \& Sanchez-Castillo C (1987) The dominance of salt in manufactured food in the sodium intake of affluent societies. Lancet 1, 426-429.

27. Mattes R \& Donelly D (1991) Relative contributions of dietary sodium sources. J Am Coll Nutr 10, 383-393.

28. Ohlhorst SD, Slavin M, Bhide JM et al. (2012) Use of iodized salt in processed foods in select countries around the world and the role of food processors. Compr Rev Food Sci F 11, 233-284.

29. Food Standards Australia New Zealand (2006) Draft Assessment Report Proposal P230: Consideration of Mandatory Fortification with Iodine for New Zealand. Wellington: FSANZ.

30. Carriquiry A (1999) Assessing the prevalence of nutrient inadequacy. Public Health Nutr 2, 23-33.

31. Gibson RS (editor) (2005) Principles of Nutritional Assessment. New York: Oxford University Press.

32. Zimmermann MB \& Andersson M (2012) Assessment of iodine nutrition in populations: past, present, and future. Nutr Rev 70, 553-570.

33. Taylor C, Carriquiry A, Bailey R et al. (2013) Appropriateness of the probability approach with a nutrient status biomarker to assess population inadequacy: a study using vitamin D. Am J Clin Nutr 97, 72-78.

34. Marmot M, Allen J, Bell R et al. (2012) WHO European review of social determinants of health and the health divide. Lancet 380, 1011-1029.

35. Zimmermann MB, Aeberli I, Torresani $\mathrm{T}$ et al. (2005) Increasing the iodine concentration in the Swiss iodized salt program markedly improved iodine status in pregnant women and children: a $5-y$ prospective national study. Am J Clin Nutr 82, 388-392. 